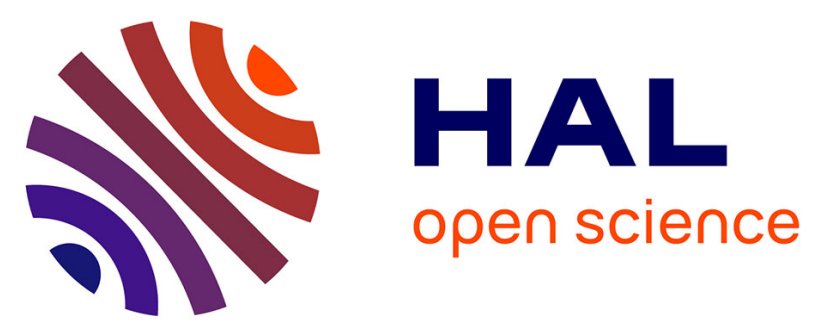

\title{
Acoustic, perceptual and clinical correlates of speech and voice in isolated dystonia: Preliminary findings
}

Marie-Charlotte Cuartero, Roxane Bertrand, Stéphane Rauzy, Lauriane

Véron-delor, Cyril Atkinson-clement, David Grabli, Marie Vidailhet, Serge Pinto

\section{To cite this version:}

Marie-Charlotte Cuartero, Roxane Bertrand, Stéphane Rauzy, Lauriane Véron-delor, Cyril Atkinsonclement, et al.. Acoustic, perceptual and clinical correlates of speech and voice in isolated dystonia: Preliminary findings. International Journal of Language and Communication Disorders, 2021, 10.1111/1460-6984.12661 . hal-03363483

\section{HAL Id: hal-03363483 https://hal.science/hal-03363483}

Submitted on 3 Jan 2022

HAL is a multi-disciplinary open access archive for the deposit and dissemination of scientific research documents, whether they are published or not. The documents may come from teaching and research institutions in France or abroad, or from public or private research centers.
L'archive ouverte pluridisciplinaire HAL, est destinée au dépôt et à la diffusion de documents scientifiques de niveau recherche, publiés ou non, émanant des établissements d'enseignement et de recherche français ou étrangers, des laboratoires publics ou privés. 
Cuartero M-C, Bertrand R, Rauzy S, Véron-Delor L, Atkinson-Clement C, Grabli D, Vidailhet M, Pinto S \& the SPIDY3 study group (2021) Acoustic, perceptual and clinical correlates of speech and voice in isolated dystonia: preliminary findings. International Journal of Language \& Communication Disorders, 56:1204-1217.

https://doi.org/10.1111/1460-6984.12661

First published in August 2021

Publisher to be acknowledged : Wiley 


\title{
Acoustic, perceptual and clinical correlates of speech and voice in isolated dystonia: preliminary findings
}

\begin{abstract}
Background: Hyperkinetic dysarthria is often present in Isolated Dystonia (ID) and is still understudied. Four main clusters of deviant speech dimensions in dystonia hyperkinetic dysarthria were initially provided: articulatory inaccuracy, phonatory stenosis, prosodic excess and prosodic insufficiency (Darley et al., 1969b).
\end{abstract}

Aim: The aim of our exploratory study was to provide preliminary data on both perceptual and acoustic analyses in relation to three out of these four main clusters.

Methods \& Procedures: Eleven patients with ID and 11 healthy controls (HC) participated in this study. Clinical/perceptual assessments and acoustic analyses of speech recordings were performed, the latter allowing for the analysis of parameters referring to aerophonatory control, voice quality, prosodic features and speech intelligibility estimated by nine listeners. Between-group statistical comparisons were performed (Wilcoxon tests, $\mathrm{p}<0.05$ ). Single-case differences between each patient and the control group were also carried out (effect size index and $t<0.05)$.

Outcomes \& Results: Between-group comparisons confirmed the presence of a 'phonatory stenosis'; in addition, deficit in aerophonatory control and hypophonia were also displayed. 'Prosodic insufficiency' was confirmed, but not at the individual level. 'Prosodic excess' manifested only in patients with marked and severe dysarthria. Correlations between altered maximum phonation time, loudness variation, speech, and articulatory rates on the one hand, and several clinical speech assessments on the other hand, were also found.

Conclusions \& Implications: From these findings, altogether, perceptual characteristics of hyperkinetic dysarthria, as suggested by Darley et al., were quantified by the acoustic 
parameters we measured. As regards to our data obtained in a small participant sample, we would suggest that Darley's clusters of excess and insufficiency prosody should be questioned in future studies involving larger numbers of dystonic patients. Our study provides novel and preliminary results that demonstrate the relevance of using quantitative measures to further characterize speech/voice deficits in patients with ID. 


\section{Introduction}

Dystonia is defined as "a movement disorder characterized by sustained or intermittent muscle contractions causing abnormal, often repetitive, movements, postures, or both" (Albanese et al., 2013). According to the more recent dystonia classification (Albanese et al., $2013 ; 2019)$, dystonia is the only motor feature in isolated dystonia (ID), contrary to combined dystonia, in which other movement disorders are present. ID can be either genetic or idiopathic. Among ID, early-onset generalized dystonia ( $<30$ years) differs from other forms because the first limb begin is the trunk then it tends to generalize to other parts of the body such as the orofacial sphere, the larynx and/or the neck. Unlike other dystonia that does not affect the trunk, they are therefore more focal or segmental. Segmental dystonia of neighbouring regions (for example Meige syndrome, the mouth and eyes are affected) and focal dystonia, a single region of the body for example, the larynx.

In ID, neck and face impairments may contribute to speech alteration, which is frequent and manifests through degradation of articulation and intelligibility, a hoarse and strained voice, with excessive variations of intensity and vocal stops (Duffy, 2013). It is usually addressed as "hyperkinetic dysarthria", mainly based on the clinical characterization of speech alterations provided by the classification of dysarthrias made by Darley et al., (1969a). Despite some limitations, this classification still represents an available tool to describe speech deficits in patients with dysarthria, including with dystonia. Four main clusters of deviant speech dimensions in dystonia hyperkinetic dysarthria were initially provided: articulatory inaccuracy, phonatory stenosis, prosodic excess and prosodic insufficiency (Darley et al., 1969b). Articulatory inaccuracy is characterized by imprecise consonants, vowels distorted and irregular articulatory breakdown. Phonatory stenosis refers to a disturbance of voice quality; perceptually, dystonic patients' voice can be harsh, strained or even strangled with 
excessive loudness variation and voice breaks. This alteration of voice quality also contributes to dysprosody (Duffy, 2013). In fact, prosodic excess is characterized by slow rate, excess stress, lengthening of pauses and phonemes, whereas prosodic insufficiency manifests by monopitch, monoloudness and reduced stress (Darley et al., 1969b). Very few details on patients' characteristics - if any - were reported on Darley's seminal articles regarding dystonia aetiology (isolated or combined) and phenomenology (focal, segmental, multifocal or generalized). Parameters identified as perceptually deviant are difficult to distinguish between dysarthria in dystonia and other types of dysarthria (Zyski \& Weisiger, 1987) and thus, it has been suggested that acoustic analyses are essential and much needed to better identify the deviant features of dysarthria (Kent et al., 1999).

Actually, studies on spasmodic dysphonia and essential vocal tremor showed that additional assessments are essential to better characterize concomitant speech disorders and inform differential diagnosis (Barkmeier-Kraemer \& Clark, 2017). However, as mentioned recently (Kreisler et al., 2016), very few studies have been conducted on speech in ID patients (Table 1). Mainly, it appears that all dimensions of speech seem altered in dystonia, including for example spasmodic dysphonia for which articulation, respiratory control and speech rhythm are disordered. Besides, some specificities might be also present according to dystonia types: e.g., voice tremor (spasmodic dysphonia) or resonance impairment (oromandibular dystonia). Acoustic analyses appear necessary to complement clinical assessments, as they allow quantification of voice/speech dimensions. From a more theoretical perspective, they can also complement and confirm - or not - perceptual deviant parameters described by Darley and collaborators. For example, a recent multiparametric voice and speech study in oromandibular dystonia showed that, in addition to expected articulation and resonance impairment, dysphonia is also quite frequent (Kreisler et al., 2016). 
Neurologists usually assess dystonia using specific (i.e., designed specifically for dystonia) global, rating scales, such as the BFM-DRS - the Burke-Fahn-Marsden Dystonia Rating Scale (Burke et al., 1985). This scale is composed of two subscales rated by the clinician: a 'movement' one (i.e., the patient examination), and a 'disability' one, based on the patient's self-report of the disability in daily-living activities. The 'movement' subscale includes only one item rating 'speech and swallowing' together, and a 'speech' item is included also in the 'disability' subscale. However, this is not sufficient to address the diversity and complexity of speech impairment in dystonia. In fact, for a more comprehensive clinical picture of dysarthria in dystonia, SLTs may use additional specific assessments. For example: voice impairment can be rated using the GRBAS (Grade, Roughness, Breathiness, Asthenia, Strain; Hirano, 1981). The Batterie d'Evaluation Clinique de la Dysarthrie (BECD - French Dysarthria Clinical Evaluation Battery; Auzou \& Rolland-Monnoury, 2006; adapted from the Frenchay Dysarthria Assessment - FDA - Enderby \& Palmer, 2008) allows the examination of different functions according to several contributors of speech dimensions (e.g., respiration, larynx, lips, jaw, mouth, tongue), often using specific oromotor tasks (e.g., oral diadochokinesis, sequential motion rate) and evaluating articulatory, prosodic deficits and speech intelligibility.

Dysarthria can induce a negative impact on communication and quality of life in patients with ID (Atkinson-Clement et al., 2019; Kreisler et al., 2016). Yet, dysarthria in ID is still understudied so far, and would benefit from a global evaluation composed of multiparametric speech analyses that could include clinical, perceptual and acoustic assessments (Barkmeier- 
Kraemer \& Clark, 2017). The study of Kreisler et al., (2016) in patients with oromandibular dystonia is one recent example that used several analyses of speech and voice disorders. While the examination of voice/speech organ function and voice/speech perceptual evaluations are performed routinely in clinical practice, acoustic analyses are rather performed in research contexts (e.g., they are more time consuming because of acoustical recordings, data preprocessing, etc.), even if automatic analyses are being developed extensively (Rusz et al., 2011, 2015, 2020). Nevertheless, acoustic analyses are helpful for quantifying voice/speech dimensions to allow deficit description, follow-up and changes following treatments.

In this context, our objective in the present preliminary study was to provide multiparametric data, and correlational analyses, from clinical, perceptual and acoustic assessments of voice/speech deficits in patients with generalized, multifocal and segmental ID. This is of particular interest since speech impairment in these kinds of ID has been scarcely studied when compared to focal dystonia (such as spasmodic dysphonia and oromandibular dystonia). In an attempt to link perceptual deficits of voice/speech in dystonia and altered acoustical features, we hypothesized that deviant clusters described by Darley et al. (1969b) in dystonic patients could be related to expected alterations of acoustic parameters calculated from several speech production tasks. More specifically, we hypothesized that: 1/ 'phonatory stenosis' could manifest via an increased number of vocal breaks, and increased jitter and shimmer (in vowel sustainance); 2/ 'prosodic insufficiency' should be related, in text reading, to reduced variation of loudness (monoloudness) and reduced variation of pitch (monopitch); and 3/ 'prosodic excess' should be related to slower speech and articulatory rates (in sequential motion rate and text reading) and possible increased variations of pitch and 
loudness. The analyses we performed did not allow for the estimation of any parameter referring to the fourth deviant cluster, i.e. 'articulatory imprecision'.

\section{Methods}

\section{Participants}

Eleven patients with isolated dystonia (8 generalized dystonia, 2 segmental dystonia and 1 multifocal dystonia) (Table 2) were recruited from the university hospitals of Grenoble, Paris, Nantes and Bordeaux (France), as part of a multicentre study (SPIDY3 clinical trial P060235, CPP3207, ENR2006-A00477-44, IDRCB2006-A00477-44). Eleven healthy age- and sexmatched controls ( 8 women, mean age $=42.6 \pm 13.2$ years, range [24-65]; 3 men, mean age $=31.7 \pm 12.6$ years, range [20-45]), without any history of speech/voice and neurological disorder, were also recruited (LPL, Aix-en-Provence, France). Beforehand, all participants signed an informed consent form, in accordance with the Declaration of Helsinki.

---------- Please insert Table 2 about here ----------

\section{Clinical assessments}

The neurological assessment was performed by neurologists using the BFM-DRS (Burke et al., 1985). Neurologists were specialized in Movement Disorders and dystonia; they performed all evaluations, based on video recordings. They were not blinded and knew that evaluations were performed for ID patients. They evaluated the patients separately, and then discussed together to reach a consensual evaluation. The cranio-cervical dystonia selfquestionnaire (CDQ24; Muller, 2004) and was used to report the impact on daily-living activities. The 36-Item Short Form Health Survey (SF-36) is a quality of life selfquestionnaire, which examines four physical and four mental subdomains, scored from 0 
(maximal disturbance) to 100 (normal) (Ware \& Sherbourne, 1992). Perceptual/clinical assessments of dysphonia and dysarthria were performed by a speech language pathologist (intra-class correlations - ICC $=0.97)$, using the GRBAS scale (Grade, Roughness, Breathiness, Asthenia, Strain; Hirano, 1981) and the perceptual assessment of the Batterie d'Evaluation Clinique de la Dysarthrie (BECD - French version of the Dysarthria Clinical Evaluation Battery; Auzou \& Rolland-Monnoury, 2006). The GRBAS is a subjective evaluation of voice quality and each of the five features is scored from 0 (normal) to 3 (severe dysphonia). The perceptual assessment of the BECD is based on the scoring of features of voice, articulation, prosody, respiration, and intelligibility; 35 criteria are scored from 0 (normal) to 4 (severely impaired).

\section{Speech recording procedure and acoustic parameters}

Each participant was recorded in a quiet, non-soundproof room. A head-mounted microphone (AKG®, model K440, Vienna, Austria) connected to a digital voice-recorder (Microtrack 24/92, M-Audio®-Avid®, Burlington, USA; Marantz PMD661 MKII recorder, USA) were used. Each participant was instructed to perform four speech production tasks (details in Table 3): maximal sustained vowel /a/; 3-second sustained vowel /a/; oral sequential motion rate (SMR - namely, the repetition of the pseudoword /pataka/); and text reading. Before analyses, audio files were blindly pre-processed (labelled, segmented and extracted) using a specific software (Praat http://www.fon.hum.uva.nl/praat/) and acoustic analyses were semiautomatically performed for the measurement of speech parameters referring to aerophonatory control, voice quality, supralaryngeal articulatory control and prosodic features (details in Table 3). Intra-class correlations (ICC) were calculated in order to ensure the intrarater reliability of this data pre-processing step, which demonstrated good-to-excellent consistency (ICC > 0.878). 


\section{Speech intelligibility}

Participants produced 10 words and 10 sentences selected randomly from predefined sets (50 words and 50 sentences available; Auzou \& Rolland-Monnoury, 2006), which were also recorded. These productions were further presented, randomly, to nine listeners (mean age $=27.8 \pm 9.1$ years), who was recruited according to the following criteria: French native speakers without any auditory, visual, neurologic or speech/language disorders; untrained and naïve about the aim of the experiment and in terms of dysarthric speech knowledge. They listened to the stimuli individually, with earphones, in a quiet room; ratings of all subjects have been averaged. Inter-class correlations confirmed the inter-rater reliability (ICC $=$ 0.761). Each stimulus was listened to by 3 different listeners, and in other words, each listener listened to a third of the total number of stimuli.

Please insert Table 3 about here

\section{Statistical analyses}

Statistical analyses were performed using Rstudio (Version 1.1.456 - (C) 2009-2018 RStudio, Inc). As data were not normally distributed (Shapiro-Wilk test), group comparisons (HC vs. patients with ID) were performed using non-parametric statistics (Wilcoxon's tests) for the predefined parameters. When data were missing, unpaired comparisons were used. Correlation analyses (Spearman's $\rho$ with Holm's correction) between all acoustic and clinical/perceptual variables, including speech intelligibility scores, were also performed for ID patients; the significant statistical threshold was set at $\mathrm{p}<0.05$. To examine single-case differences between each ID patient and the HC group, we used the Singlims_ES.exe program developed by Crawford, Garthwaite, \& Porter (2010). This method provides 
estimates of the effect size for the difference of the mean \pm SD of every variable between each ID single-case and the control group (as an effect size index and the $t$ value statistically significant at 0.05$)$.

\section{Results}

\section{Clinical/perceptual assessments, self-assessments \& speech intelligibility}

BFM-DRS scores (Table 4.a), as well as SF-36 and CDQ-24 self-assessments (Table 4.b), were highly heterogeneous across ID patients. This was also the case for the BECD (Table 4.c) and GRBAS (Table 4.d) scores. More specifically, four patients suffering from generalised (P01, P05 and P06) or multifocal (P03) dystonia displayed marked or severe dysarthria (Perceptive score of the BECD>10; Table 4.b) and severe dysphonia (score G=3 on the GRBAS scale; Table 4.c).

Regarding speech intelligibility (Table 4.e), three (P01, P03 and P06) among these four patients displayed the lowest scores for both word and sentence intelligibility; the listeners qualitatively rated speech intelligibility as unintelligible. Between-group comparisons displayed that word intelligibility of ID patients was significantly $(\mathrm{p}=0.004)$ reduced $(66 \% \pm 25 \% ;[\min =2 \%, \max =91 \%])$ when compared to $\mathrm{HC}(86 \% \pm 5 \% ;[\mathrm{min}=79 \%$, $\max =92 \%]$ ); on the contrary, sentence intelligibility was not significantly different between groups. Speech intelligibility was qualitatively rated as "abnormal but clear" (word score = $1.23 \pm 1.22,[\min =0.2, \max =3.9] ;$ sentence $s c o r e=1.24 \pm 1.29,[\min =0.3, \max =3.9])$ for ID patients, which was significantly $(\mathrm{p}<0.001)$ different from the normal range of the HC (word score $=0.35 \pm 0.12,[\min =0.2, \max =0.5] ;$ sentence score $=0.16 \pm 0.10,[\min =0, \max =0.3])$. 


\section{Acoustic parameters}

Most of the acoustic parameters calculated from the maximum (Table 5.a) and 3-second (Table 5.b) sustained vowels demonstrated significant group differences between $\mathrm{HC}$ and patients with ID. Single-case statistics highlighted individually these trends for the 3 -second sustained vowel, except for the MPT (individual data not shown). For the sequential motion rate (SMR) task, no significant group difference was found for all variables (Table 5.c). However, the single case analysis showed that patient P06, when compared to the HC group (individual data not shown), had significant longer articulatory rate, speech and pause proportions $(t<0.05)$. For the text reading, SPL-SD differed significantly $(\mathrm{p}<0.05)$ between HC and ID patients (Table 5.d). No significant statistical difference was found between groups for the other variables extracted from the text reading. However, the single case analysis showed that patients P01, P02, P03 and P05 had significant differences when compared to the $\mathrm{HC}$ group for variables of speech temporal organization (individual data not shown), $(t<0.05)$. Patient P03 had a decrease in the number of syllables (omission of 16 syllables, in average) and conversely, patients P02 and P05 had a higher number of syllables (11 and 13 repeated syllables, respectively). Patient P05 had more pauses, an increase of pause duration and a slower speech rate. Total text duration and total speech duration were longer in patients $\mathrm{P} 01, \mathrm{P} 03$ and $\mathrm{P} 05$. A slower articulatory rate was found for the patients $\mathrm{P} 01$ and P03. Note that the calculation of the text reading variables was not possible at all for patient 6 , who was unintelligible, and therefore excluded from the analyses. 


\section{Correlation analyses}

Significant correlations $(\rho>-0.90 ; \mathrm{p}<0.05)$ were found between the MPT and several clinical assessments and perceptual speech evaluation: speech/swallowing item of the BFM-DRS, qualitative rating of speech intelligibility and voice quality assessed by the GRBAS. Shorter MPTs, reflecting a difficulty of aerophonatory control, were correlated with higher scores (i.e., altered function) of clinical/perceptual speech and voice assessments. SPL-SD (3-second sustained vowel) and the R-dimension of the GRBAS were significantly correlated $(\rho>0.94 ; \mathrm{p}$ $=0.01$, voice roughness being associated with a highly variable SPL. Speech rate (text reading) was significantly correlated with the S-dimension of the GRBAS $(\rho>0.92 ; p=0.04)$ and the BECD naturalness/bizarreness item $(\rho>-0.94 ; \mathrm{p}=0.02)$. Articulatory rate (text reading) was also correlated significantly with the naturalness/bizarreness BECD item ( $\rho$ >$0.94 ; \mathrm{p}=0.02)$

Significant correlations were found between acoustic parameters: HNR and shimmer ( $\rho=-$ $0.90 ; \mathrm{p}=0.05)$, SPL-SD (3-second sustained vowel) and jitter $(\rho=-0.90 ; \mathrm{p}=0.03) ;$ speech proportion $(\mathrm{SMR})$ and pause proportion $(\mathrm{SMR})(\rho=-1 ; \mathrm{p}=0.03)$; speech rate (text reading) and articulatory rate (text reading) $(\rho=0.95 ; \mathrm{p}=0.001)$ and number of pauses (text reading) $(\rho=-0.93 ; \mathrm{p}=0.001)$

This was also the case for clinical/perceptual assessments : correlations were found between G-dimension and A-dimension of the GRBAS ( $\rho=0.94 ; \mathrm{p}=0.01)$, qualitative rating of intelligibility $(\rho=0.90 ; \mathrm{p}=0.04)$, BFM-DRS speech \& swallowing item $(\rho=0.90 ; \mathrm{p}=0.05)$, BECD naturalness/bizarreness item $(\rho=0.90 ; \mathrm{p}=0.05)$, BECD perceptive score $(\rho=0.92 ; \mathrm{p}=$ 0.03); between BECD total score and BECD phonetic realization item $(\rho=0.93 ; \mathrm{p}=0.01)$, BECD prosody item $(\rho=0.92 ; \mathrm{p}=0.03)$, BECD perceptive score $(\rho=0.97 ; \mathrm{p}=0.001)$; and 
between BECD perceptive score and BECD phonetic realization item $(\rho=0.95 ; \mathrm{p}=0.001)$, BECD prosody item $(\rho=0.91 ; \mathrm{p}=0.04)$.

No correlation was found between patient-reported outcome measures (CDQ-24 and SF-36) and any other clinical score and acoustic parameters.

\section{Discussion}

We originally hypothesized that deviant clusters described by Darley et al. (1969) in dystonic patients could be related to expected alterations of acoustic parameters, calculated from the several speech production tasks we performed in this exploratory study. First, between-group comparisons confirmed, for parameters of 3-second sustained vowel, the presence of a 'phonatory stenosis', which manifested by increased number of vocal breaks, and shimmer; in addition, original data are provided as regards to the increase F0-SD and SPL-SD, and reduction of MPT (deficit in aerophonatory control), HNR (harsh voice), and loudness (hypophonia). Second, even if some 'prosodic insufficiency' was confirmed by the reduction of SPL-SD (monoloudness) for the text reading, this has to be taken with precaution since individual analyses did not reveal any significant difference. Interestingly, it does not seem that patients displayed any reduction of F0-SD for the text reading, questioning the presence of monopitch in ID dysarthria. Finally, no increase of variations of pitch and loudness and no slower speech and articulatory rates were found in patients with ID when compared to controls, for the text reading. A 'prosodic excess' manifested by slower speech or articulatory rates, as well as prolonged speech duration, were found only in patients with marked and severe dysarthria. From these findings, altogether, perceptual characteristics of hyperkinetic dysarthria, as suggested by Darley et al., were somehow quantified by the acoustic parameters we measured. 


\section{Isolated Dystonia alters aerophonatory control and voice quality}

At the group level, MPT was altered for ID patients compared with controls, and it could represent an indicator of the aero-phonatory control and stability between the respiratory and phonatory systems. However, this was not the case when using the single-case individual statistics. Alteration of respiratory control per se may contribute to the decrease in MPT, by reducing oral airflow. In fact, faster respiratory rate, less breathing rhythmic patterns, decreased lung volume, apnea-like periods with decreased arterial blood flow during quiet breathing and monologue have been reported in patients with ID (LaBlance \& Rutherford, 1991). Speech intelligibility was also altered significantly in these patients with ID, in relation with the alterations of respiratory dynamics (LaBlance \& Rutherford, 1991). Our findings seem to be in line with these physiological manifestations. Trunk dystonia can also affect voice/speech by generating abnormal respiratory movements (Duffy, 2013, p. 205), possibly contributing to the phonatory stenosis described by Darley et al., (1969b).

The clinical/perceptual ratings performed using the BECD reported only 4/11 patients with a moderate-to-severe impairment of voice quality (item $1 \geq 2$ ). Dysphonia evaluated clinically by the GRBAS scale was found for 5/11 patients (G-dimension $\geq 2$; Table 4d). Moreover, nine patients out of the 11 displayed cervical dystonia (BFM-DRS item neck $\geq 4$; Table 4a), which can also affect voice/speech by generating torsions of the neck and/or participating in the elevation of the larynx (Duffy, 2013). These results are consistent with the impact of cervical dystonia in quality of life: seven patients who had severe cervical dystonia (CDQ-24 scores $\geq 50$, Table $\mathbf{4 b}$ ) perceived badly the impact of dystonia on their quality of life and daily activity. Group comparisons of parameters measured in the 3-second sustained vowel displayed significant differences between HC and ID patients. Patients with ID showed in our 
study increased F0-SD and SPL-SD, and a higher number of voice breaks, confirming specific features of hyperkinetic dysarthria (Duffy, 2013). Alterations of loudness, HNR and shimmer were found for all patients, highlighting the importance of dysphonia and hypophonia among speech and voice deficits in ID, as previously suggested in patients with oromandibular dystonia (Kreisler et al., 2016). Consequently, complementary to perceptual assessments, acoustic analysis appears relevant to quantify more precisely subtle deficits that could contribute to both description and management of voice features.

\section{Prosodic features in Isolated Dystonia}

For the text reading, differences between $\mathrm{HC}$ and patients with ID displayed a so-called 'prosodic insufficiency' associated with a single decreased loudness variation, i.e. a monoloudness. No monopitch was found. Regarding 'prosodic excess', no increase of variations of pitch and loudness and no slower speech and articulatory rates were found in patients with ID when compared to controls. A 'prosodic excess' manifested by slower speech or articulatory rates, as well as prolonged speech duration, were found only in patients with marked and severe dysarthria. In fact, our single-case findings pointed out trends towards an impairment of speech temporal parameters for four patients with ID, as revealed by several bradylalic characteristics (Darley et al., 1969b). Such an alteration of speech temporal organization can be related to the degree of severity of dysarthria: actually, four patients with a BECD perceptual score above 10/20 have also an impairment of prosodic parameters. More particularly, these patients presented with either an isolated generalized (3/4) or multifocal (1/4) dystonia (Table 2), with impacts on neck, mouth, trunk and difficulties in speech/swallowing. Furthermore, these patients have a higher severity of speech and voice dimensions estimated by the BECD perceptual scores. While in the description of Darley et al., (1969) dysprosody appeared as an almost systematic cluster present in hyperkinetic 
dysarthria in ID patients, such impairment was not found in all patients we studied here. Further studies in a larger number of patients with ID and focusing on dysprosodic features are still needed to draw more robust conclusions on this point.

A more general alteration of speech temporal organization seems to be displayed by the patients studied here, in relation with the alteration of assembling laryngeal and supralaryngeal gestures into "motor plans" for syllables and words (Ackermann et al., 2014). This might have been the case for our patients in the text reading as it is a more complex task than, for example, the SMR that was rather preserved in patients with ID when compared with HC. As we pointed out here, heterogeneity of speech impairment can be explained by the site of body parts affected; moreover, the age of disease onset, duration and severity also contribute to the expression of dysarthria and dysphonia in ID (Tripoliti, 2007). In fact, dystonia of any anatomical structure involved in the speech system can have prominent effects on prosody (Duffy, 2013).

\section{Added value of multiparametric approach on voice and speech in ID}

Our exploratory study demonstrated that quantifying speech and voice deficits, together with with perceptual/clinical assessments, is essential to provide a thorough speech evaluation in ID. A multiparametric approach appears necessary since none of specific perceptual/clinical assessments can reveal all deficits of speech/voice features that can be displayed in ID dysarthria: e.g., the single speech/swallowing item of the BFM-DRS could not disentangle between speech and voice alterations, or give any precision regarding such alterations, compared to the more accurate description provided by either the BECD (based on Darley's evaluation criteria) or the GRBAS. 
The correlational analyses we performed allowed us to determine the relationships between the different kinds of evaluation carried out. MPT was correlated with the qualitative rating of speech intelligibility, the BFM-DRS speech/swallowing item, GRBAS subscores G (grade) and A (asthenia). Actually, the shorter was the MPT, the more altered was voice quality (dysphonia, hypotonic voice) and the more severe was hypophonia (asthenia of the GRBAS could also underlie a mechanism explaining potentially the observed loss of loudness in the patients studied here; Hirano, 1981). Other correlations between clinical/perceptual and acoustic variables were found: (1) higher SPL-SD (3-second sustained vowel) was related to severe roughness (GRBAS); (2) slower speech rate (text reading) was connected to strained voice (GRBAS) and speech naturalness/bizarreness (BECD); and (3) slower articulatory rate (text reading) correlated with speech naturalness/bizarreness (BECD). Thus, in patients with ID, MPT and SPL-SD can be identified as good indicators of voice quality, whereas speech and articulatory rates rather inform on speech naturalness.

Acoustic analyses pointed out that, as expected, patients with the more severe dysarthria (assessed perceptually) present with the more altered acoustic parameters; more interestingly, patients with mild dysarthria (assessed perceptually) did also present with alterations of acoustic features, related to voice quality deficits. Running speech and non-speech tasks is of major importance: patients with moderate/severe dysarthria displayed alterations of acoustic features in both (simple, non-speech) phonation tasks (MPT, 3-second sustainance vowel /a/) and (more complex, speech) text reading; patients with mild dysarthria only displayed voice quality impairment revealed by (non-speech) phonation tasks.

We were confronted with a large symptomatic heterogeneity of a small sample of patients: ID can induce either a negative impact on quality of life (SF-36 self-assessment) in patients with 
both mild/moderate (e.g., patient P09, Table 4) and marked/severe dysarthria (e.g., patient $\mathrm{P} 01$, Table 4); or positive impact in both patients with mild/moderate (e.g., patient P07, Table 4) and marked/severe dysarthria (patient P03, Table 4). This might explain the reason why no correlation between self-assessment of quality of life and speech (perceptual, clinical and acoustic) evaluation was found. It seems that severity of dysarthria and intelligibility scores are not reflected systematically by self-reported measures. SF-36 does not consider specifically functional impact of dysarthria, which can be evaluated by dedicated selfquestionnaires (e.g., dysarthria impact profile; Walshe et al., 2009; Atkinson-clement et al., 2019). For further studies, it is important to include the evaluation of such dimension is order to provide a thorough, multiparametric, and holistic speech evaluation in dystonia.

\section{Limitations}

We have to acknowledge here that the number of patients included in this study can be a limitation to generalization of speech impairment in ID. The limited speech production samples acquired, and the unbalanced sex distribution of our patient group are additional limitations that have to be acknowledged. Moreover, the analyses we performed did not allow for the estimation of any parameter referring to the fourth deviant cluster identified by Darley et al., i.e. 'articulatory imprecision'. Perceptual scoring of the BECD did reveal impairment of at least three articulatory features (altered phoneme duration - most often prolonged, imprecise consonants and/or vowels) in the four patients previously identified and displaying a marked/severe dysarthria. Thus, in order to draw more robust conclusion on this dimension, a specific analysis of articulatory variables by using more dedicated speech/non-speech tasks, would be necessary in further studies. 


\section{Conclusion}

Multiparametric analysis may be beneficial but not necessary to get a better understanding of the speech dimensions affected in speakers with ID. Data of acoustic features of speech impairments in ID are still missing in the literature, and our study provides original preliminary results that contribute to refine speech/voice deficit characterization in patients with ID. Our study showed that dysphonia/hypophonia are present in all patients with ID we studied here, whatever the severity of dystonia and dysarthria. However, two subgroups of patients were identified: one including patients with mild to moderate dysarthria, presenting with voice quality impairment only; and a second one, involving patients with moderate to severe dysarthria, and displaying disorder of speech temporal organization in addition to voice quality impairment. As regards to our data obtained in a small participant sample, we would suggest that Darley's clusters of excess and insufficiency prosody should be questioned in future studies involving larger numbers of dystonic patients. Performing both clinical/perceptual assessments and acoustic measurements in order to capture the severity of speech/voice impairment and quantify alterations of several speech dimensions is of major importance. Due to the heterogeneity of dystonia symptoms, and the multiple aspects of speech dimensions impairment, there will be a need of creating several subgroups from a larger cohort of ID patients, underlying specific phenotypes of patients.

\section{References}

Ackermann, H., Hage, S. R., \& Ziegler, W. (2014). Brain mechanisms of acoustic communication in humans and nonhuman primates: An evolutionary perspective.

Behavioral and Brain Sciences, 37(06), 529-546. https://doi.org/10.1017/S0140525X13003099

Adams, S. G., Hunt, E. J., Irish, J. C., Charles, D. A., Lang, A. E., Durkin, L. C., \& Wong, D. L. (1995). Comparison of botulinum toxin injection procedures in adductor spasmodic dysphonia. The Journal of Otolaryngology, 24(6), 345-351. 
Albanese, A., Sorbo, F. D., Comella, C., Jinnah, H. A., Mink, J. W., Post, B., Vidailhet, M., Volkmann, J., Warner, T. T., Leentjens, A. F. G., Martinez-Martin, P., Stebbins, G. T., Goetz, C. G., \& Schrag, A. (2013). Dystonia rating scales: Critique and recommendations: Dystonia Rating Scales. Movement Disorders, 28(7), 874-883. https://doi.org/10.1002/mds.25579

Atkinson-Clement, C., Letanneux, A., Baille, G., Cuartero, M.-C., Véron-Delor, L., Robieux, C., Berthelot, M., Robert, D., Azulay, J.-P., Defebvre, L., Ferreira, J., Eusebio, A., Moreau, C., \& Pinto, S. (2019). Psychosocial Impact of Dysarthria: The Patient-Reported Outcome as Part of the Clinical Management. Neuro-Degenerative Diseases, 19(1), 12 21. https://doi.org/10.1159/000499627

Auzou, P., \& Rolland-Monnoury, V. (2006). BECD: Batterie d'évaluation clinique de la dysarthrie. Ortho édition.

Baken, R. J., \& Orlikoff, R. F. (2000). Clinical measurement of speech and voice (2nd ed). Singular Thomson Learning.

Barkmeier-Kraemer, J. M., \& Clark, H. M. (2017). Speech-Language Pathology Evaluation and Management of Hyperkinetic Disorders Affecting Speech and Swallowing Function. Tremor and Other Hyperkinetic Movements, Tremor and Other Hyperkinetic Movements-. https://doi.org/10.7916/d8z32b30

Buckley, D. P., Cadiz, M. D., Eadie, T. L., \& Stepp, C. E. (2020). Acoustic Model of Perceived Overall Severity of Dysphonia in Adductor-Type Laryngeal Dystonia. Journal of Speech, Language, and Hearing Research, 63(8), 2713-2722. https://doi.org/10.1044/2020_JSLHR-19-00354

Burke, R. E., Fahn, S., Marsden, C. D., Bressman, S. B., Moskowitz, C., \& Friedman, J. (1985). Validity and reliability of a rating scale for the primary torsion dystonias. Neurology, 35(1), 73-77.

Cannito, M. P., Sapienza, C. M., Woodson, G., \& Murry, T. (2003). Adductor spasmodic dysphonia : Relationships between acoustic indices and perceptual judgments. The Journal of the Acoustical Society of America, 113(4), 2259-2259. https://doi.org/10.1121/1.4780472

Cimino-Knight, A. M., \& Sapienza, C. M. (2001). Consistency of Voice Produced by Patients With Adductor Spasmodic Dysphonia : A Preliminary Investigation. Journal of Speech, Language, and Hearing Research, 44(4), 793-802. https://doi.org/10.1044/1092$4388(2001 / 062)$ 
Crawford, J. R., Garthwaite, P. H., \& Porter, S. (2010). Point and interval estimates of effect sizes for the case-controls design in neuropsychology: Rationale, methods, implementations, and proposed reporting standards. Cognitive Neuropsychology, 27(3), 245-260. https://doi.org/10.1080/02643294.2010.513967

Darley, F. L., Aronson, A. E., \& Brown, J. R. (1969a). Differential diagnostic patterns of dysarthria. Journal of Speech and Hearing Research, 12(2), 246-269.

Darley, F. L., Aronson, A. E., \& Brown, J. R. (1969b). Clusters of deviant speech dimensions in the dysarthrias. Journal of Speech and Hearing Research, 12(3), 462-496.

Duffy, J. R. (2013). Hyperkinetic dysarthrias. In Motor speech disorders: Substrates, differential diagnosis, and management (Third edition, pp. 191-221). Elsevier.

Edgar, J. D., Sapienza, C. M., Bidus, K., \& Ludlow, C. L. (2001). Acoustic Measures of Symptoms in Abductor Spasmodic Dysphonia. Journal of Voice, 15(3), 362-372. https://doi.org/10.1016/S0892-1997(01)00038-8

Enderby, P. M., Palmer, R., \& Pro-Ed (Firm). (2008). Frenchay Dysarthria Assessment (FDA-2) (2nd ed.). Pro-ED. https://books.google.fr/books?id=BOqDZwEACAAJ

Hammen, V. L., \& Yorkston, K. M. (1996). Speech and pause characteristics following speech rate reduction in hypokinetic dysarthria. Journal of Communication Disorders, 29(6), 429-444; quiz 444-445.

Hendrix, C. M., \& Vitek, J. L. (2012). Toward a network model of dystonia: Toward a network model of dystonia. Annals of the New York Academy of Sciences, 1265(1), 4655. https://doi.org/10.1111/j.1749-6632.2012.06692.x

Hertegård, S., Granqvist, S., \& Lindestad, P. A. (2000). Botulinum toxin injections for essential voice tremor. The Annals of Otology, Rhinology, and Laryngology, 109(2), 204-209. https://doi.org/10.1177/000348940010900216

Hirano, M. (1981). Clinical examination of voice. Springer-Verlag.

Hlavnička, J., Tykalová, T., Ulmanová, O., Dušek, P., Horáková, D., Růžička, E., Klempiřr, J., \& Rusz, J. (2020). Characterizing vocal tremor in progressive neurological diseases via automated acoustic analyses. Clinical Neurophysiology, 131(5), 1155-1165. https://doi.org/10.1016/j.clinph.2020.02.005

Kahn, L., \& Jordaan, H. (2001). The swallowing and voicing characteristics of pharyngeal dystonia : A single case report. The South African Journal of Communication Disorders = Die Suid-Afrikaanse Tydskrif Vir Kommunikasieafwykings, 48, 21-31.

Kent, R. D., Weismer, G., Kent, J. F., Vorperian, H. K., \& Duffy, J. R. (1999). Acoustic 
studies of dysarthric speech: Methods, progress, and potential. Journal of Communication Disorders, 32(3), 141-180, 183-186; quiz 181-183, 187-189.

Kiyuna, A., Maeda, H., Higa, A., Shingaki, K., Uehara, T., \& Suzuki, M. (2014). Brain activity related to phonation in young patients with adductor spasmodic dysphonia. Auris Nasus Larynx, 41(3), 278-284. https://doi.org/10.1016/j.anl.2013.10.017

Kreisler, A., Verpraet, A.-C., Veit, S., Pennel-Ployart, O., Béhal, H., Duhamel, A., \& Destée, A. (2016). Clinical Characteristics of Voice, Speech, and Swallowing Disorders in Oromandibular Dystonia. Journal of Speech Language and Hearing Research, 59(5), 940. https://doi.org/10.1044/2016_JSLHR-S-15-0169

LaBlance, G. R., \& Rutherford, D. R. (1991). Respiratory dynamics and speech intelligibility in speakers with generalized dystonia. Journal of Communication Disorders, 24(2), 141156.

Lee, A., Furuya, S., Morise, M., Iltis, P., \& Altenmüller, E. (2014). Quantification of instability of tone production in embouchure dystonia. Parkinsonism \& Related Disorders, 20(11), 1161-1164. https://doi.org/10.1016/j.parkreldis.2014.08.007

Lee, A., Voget, J., Furuya, S., Morise, M., \& Altenmüller, E. (2016). Quantification of sound instability in embouchure tremor based on the time-varying fundamental frequency. Journal of Neural Transmission, 123(5), 515-521. https://doi.org/10.1007/s00702-016$1533-6$

Ludlow, C. L. (2011). Spasmodic Dysphonia: A Laryngeal Control Disorder Specific to Speech. Journal of Neuroscience, 31(3), 793-797. https://doi.org/10.1523/JNEUROSCI.2758-10.2011

Ludlow, Christy L., Adler, C. H., Berke, G. S., Bielamowicz, S. A., Blitzer, A., Bressman, S. B., Hallett, M., Jinnah, H. A., Juergens, U., Martin, S. B., Perlmutter, J. S., Sapienza, C., Singleton, A., Tanner, C. M., \& Woodson, G. E. (2008). Research priorities in spasmodic dysphonia. Otolaryngology-Head and Neck Surgery, 139(4), 495-505. https://doi.org/10.1016/j.otohns.2008.05.624

Ludlow, Christy L., \& Connor, N. P. (1987). Dynamic Aspects of Phonatory Control in Spasmodic Dysphonia. Journal of Speech, Language, and Hearing Research, 30(2), 197-206. https://doi.org/10.1044/jshr.3002.197

Lundy, D. S., Roy, S., Xue, J. W., Casiano, R. R., \& Jassir, D. (2004). Spastic/spasmodic vs. tremulous vocal quality: Motor speech profile analysis. Journal of Voice, 18(1), 146-152. https://doi.org/10.1016/j.jvoice.2003.12.001 
Mor, N., Simonyan, K., \& Blitzer, A. (2018). Central voice production and pathophysiology of spasmodic dysphonia: Central Voice Production and SD. The Laryngoscope, 128(1), 177-183. https://doi.org/10.1002/lary.26655

Morris, A. E., Norris, S. A., Perlmutter, J. S., \& Mink, J. W. (2018). Quantitative, clinically relevant acoustic measurements of focal embouchure dystonia : Acoustic Measurements of Embouchure Dystonia. Movement Disorders, 33(3), 449-458.

https://doi.org/10.1002/mds.27298

Muller, J. (2004). Craniocervical dystonia questionnaire (CDQ-24): Development and validation of a disease-specific quality of life instrument. Journal of Neurology, Neurosurgery \& Psychiatry, 75(5), 749-753. https://doi.org/10.1136/jnnp.2003.013441

Olszewski, A. E., Shen, L., \& Jiang, J. J. (2011). Objective methods of sample selection in acoustic analysis of voice. The Annals of Otology, Rhinology, and Laryngology, 120(3), 155-161. https://doi.org/10.1177/000348941112000303

Rojas, G. V. E., Ricz, H., Tumas, V., Rodrigues, G. R., Toscano, P., \& Aguiar-Ricz, L. (2017). Vocal Parameters and Self-Perception in Individuals With Adductor Spasmodic Dysphonia. Journal of Voice, 31(3), 391.e7-391.e18.

https://doi.org/10.1016/j.jvoice.2016.09.029

Rusz, J., Cmejla, R., Ruzickova, H., \& Ruzicka, E. (2011). Quantitative acoustic measurements for characterization of speech and voice disorders in early untreated Parkinson's disease. The Journal of the Acoustical Society of America, 129(1), 350-367. https://doi.org/10.1121/1.3514381

Rusz, J., Hlavnička, J., Čmejla, R., \& Růžička, E. (2015). Automatic Evaluation of Speech Rhythm Instability and Acceleration in Dysarthrias Associated with Basal Ganglia Dysfunction. Frontiers in Bioengineering and Biotechnology, 3. https://doi.org/10.3389/fbioe.2015.00104

Rusz, J., Tykalova, T., Ramig, L. O., \& Tripoliti, E. (2020). Guidelines for Speech Recording and Acoustic Analyses in Dysarthrias of Movement Disorders. Movement Disorders, mds.28465. https://doi.org/10.1002/mds.28465

Sapienza, C. M., Murry, T., \& Brown, W. S. (1998). Variations in adductor spasmodic dysphonia:Acoustic evidence. Journal of Voice, 12(2), 214-222. https://doi.org/10.1016/S0892-1997(98)80041-6 
Sapienza, C. M., Walton, S., \& Murry, T. (1999). Acoustic Variations in Adductor Spasmodic Dysphonia as a Function of Speech Task. Journal of Speech, Language, and Hearing Research, 42(1), 127-140. https://doi.org/10.1044/jslhr.4201.127

Sapienza, C. M., Walton, S., \& Murry, T. (2000). Adductor spasmodic dysphonia and muscular tension dysphonia : Acoustic analysis of sustained phonation and reading. Journal of Voice, 14(4), 502-520. https://doi.org/10.1016/S0892-1997(00)80008-9

Siemons-Lühring, D. I., Moerman, M., Martens, J.-P., Deuster, D., Müller, F., \& Dejonckere, P. (2009). Spasmodic dysphonia, perceptual and acoustic analysis: Presenting new diagnostic tools. European Archives of Oto-Rhino-Laryngology, 266(12), 1915-1922. https://doi.org/10.1007/s00405-009-0995-7

Simonyan, K., Tovar-Moll, F., Ostuni, J., Hallett, M., Lewin-Smith, M. R., Rushing, E. J., Vortmeyer, A. O., \& Ludlow, C. L. (2009). Focal white matter changes in spasmodic dysphonia: A combined DTI and neuropathological study. 24.

Vitek, J. L. (2002). Pathophysiology of dystonia: A neuronal model. Movement Disorders, 17(S3), S49-S62. https://doi.org/10.1002/mds.10142

Walshe M, Peach RK, Miller N: Dysarthria impact profile: development of a scale to measure psychosocial effects. Int J Lang Commun Disord 2009;44:693-715.

Ware, J. E., \& Sherbourne, C. D. (1992). The MOS 36-item short-form health survey (SF-36). I. Conceptual framework and item selection. Medical Care, 30(6), 473-483.

Wolfe, V. I., \& Bacon, M. (1976). Spectrographic Comparison of Two Types of Spastic Dysphonia. Journal of Speech and Hearing Disorders, 41(3), 325-332. https://doi.org/10.1044/jshd.4103.325

Zyski, B. J., \& Weisiger, B. E. (1987). Identification of dysarthria types based on perceptual analysis. Journal of Communication Disorders, 20(5), 367-378.

Zwirner, P., Murry, T., \& Woodson, G. E. (1993). Perceptual-acoustic relationships in spasmodic dysphonia. Journal of Voice, 7(2), 165-171. https://doi.org/10.1016/S08921997(05)80347-9 
Table 1. Studies reporting acoustic features in Isolated Dystonia.

\begin{tabular}{|c|c|c|c|}
\hline Authors & Dystonia & Measured parameters & Function assessed \\
\hline \multirow{5}{*}{$\begin{array}{l}\text { Zraik et al., } 1993 \text { (in Duffy, } \\
2013 \text { ) } \\
\text { La Pointe et al., } 1994 \text { (in Duffy, } \\
\text { 2013) } \\
\text { Hlavnička et al., } 2020\end{array}$} & \multirow{5}{*}{$\mathrm{CD}$} & Maximum phonation time & $\begin{array}{l}\text { Aerophonatory } \\
\text { control }\end{array}$ \\
\hline & & $\begin{array}{l}\text { Decrease HNR } \\
\text { Increase Jitter } \\
\text { Increase Shimmer } \\
\text { Increase Vowel duration } \\
\text { Voice tremor }\end{array}$ & Voice quality \\
\hline & & Increase Consonant duration & Articulation \\
\hline & & $\begin{array}{l}\text { Increase AMR } \\
\text { Increase SMR }\end{array}$ & Speech rhythm \\
\hline & & $\begin{array}{l}\text { Increased mean and range } \\
\text { pitch }\end{array}$ & Prosodic features \\
\hline \multirow{4}{*}{$\begin{array}{l}\text { Wolfe \& Bacon, } 1976 \\
\text { Ludlow \& Connor, } 1987 \\
\text { Zwirner et } \text { al., } 1993 \\
\text { Adams et } \text { al., } 1995 \\
\text { Sapienza et } \text { al., 1997; 1999; } 2000 \\
\text { Hertegrad et } \text { al., } 2000 \\
\text { Cimino-Knight \& Sapienza } \\
\text { (2001) } \\
\text { Edgar et } \text { al., } 2001 \\
\text { Lundy et } \text { al., } 2004 \\
\text { Ludlow et } \text { al., } 2008 \\
\text { Ludlow, 2011 } \\
\text { Rojas et al., } 2017 \\
\text { Buckley et al., } 2020\end{array}$} & \multirow[t]{4}{*}{ AdSD } & $\begin{array}{l}\text { Aperiodicity of phonation } \\
\text { Voice breaks } \\
\text { Frequency shifts } \\
\text { Decrease F0 } \\
\text { Decrease loudness } \\
\text { Increase jitter } \\
\text { Increase shimmer } \\
\text { Vocal tremor } \\
\text { Voice onset-time delay }\end{array}$ & Voice quality \\
\hline & & $\begin{array}{l}\text { Breakdown formant structures } \\
\text { Interruption in articulation }\end{array}$ & Articulation \\
\hline & & $\begin{array}{l}\text { Slow speech rate } \\
\text { Increase pause time }\end{array}$ & Speech rhythm \\
\hline & & $\begin{array}{l}\text { High variability F0 } \\
\text { Loudness fluctuations }\end{array}$ & Prosodic features \\
\hline \multirow{4}{*}{$\begin{array}{l}\text { Wolfe \& Bacon, } 1976 \\
\text { Ludlow \& Connor, } 1987 \\
\text { Cannito et } \text { al., } 1996 \\
\text { Ludlow et al., } 2008 \\
\text { Ludlow, } 2011\end{array}$} & \multirow{4}{*}{$\mathrm{AbSD}$} & $\begin{array}{l}\text { Prolonged breathy breaks } \\
\text { Increase aspiration time }\end{array}$ & Respiratory control \\
\hline & & $\begin{array}{l}\text { Aperiodicity } \\
\text { Voice breaks } \\
\text { Increase F0 } \\
\text { F0 changes } \\
\text { Vocal over-abduction } \\
\text { Voiceless phonemes } \\
\text { Voice onset-time delay } \\
\text { Long breaks } \\
\text { Loss of energy in higher } \\
\text { formant } \\
\text { Breakdown of formant } \\
\text { structure }\end{array}$ & Voice quality \\
\hline & & $\begin{array}{l}\text { Breakdown formant structures } \\
\text { Long voice onset time } \\
\text { Increase articulation time }\end{array}$ & Articulation \\
\hline & & $\begin{array}{l}\text { Pitch breaks } \\
\text { Loudness fluctuations }\end{array}$ & Prosodic features \\
\hline \multirow[b]{2}{*}{ Kreisler et al., 2016} & \multirow[b]{2}{*}{ OMD } & Disrupted breathing & Respiratory control \\
\hline & & $\begin{array}{l}\text { Harsh voice } \\
\text { Intensity fluctuation } \\
\text { Dysphonia }\end{array}$ & Voice quality \\
\hline
\end{tabular}




\begin{tabular}{|l|l|l|l|}
\hline & & Hypernasality & Resonance \\
\cline { 3 - 4 } & \multirow{2}{*}{$\begin{array}{l}\text { Imprecise consonants } \\
\text { Co-articulation }\end{array}$} & Articulation \\
\hline Lee et al., 2016; 2014 & \multirow{2}{*}{ FED } & $\begin{array}{l}\text { Increase shimmer } \\
\text { Vocal tremor } \\
\text { High variability F0 }\end{array}$ & Voice quality \\
\cline { 3 - 4 } & $\begin{array}{l}\text { Pitch inaccuracy } \\
\text { Pitch breaks }\end{array}$ & Prosodic features \\
\hline Kahn \& Jordaan, 2001 & Po & $\begin{array}{l}\text { Voice onset-time delay } \\
\text { Decrease F0 } \\
\text { Increase shimmer }\end{array}$ & Voice quality \\
\hline
\end{tabular}

AdSD: Adductor spasmodic dysphonia; AbSD: Abductor Spasmodic Dysphonia; AMR: Alternative motion rate; CD: cervical dystonia; OMD: Oromandibular dystonia; FED: focal embouchure dystonia; PD: pharyngeal dystonia; HNR: Harmonic Noise Ratio; F0: Fundamental frequency; SMR: sequential motion rate. 
Table 2. Demographics data of patients with Isolated Dystonia.

\begin{tabular}{ccccc}
\hline Patients & Gender & Age & $\begin{array}{c}\text { Duration of } \\
\text { disease }\end{array}$ & Body areas affected by dystonia \\
\hline $\mathbf{1}$ & F & 38 & 31 & $(2)(3)(4)(5)(6)(7)$ \\
\hline $\mathbf{2}$ & F & 24 & 19 & $(1)(4)(5)(6)(7)$ \\
$\mathbf{3}$ & M & 30 & 21 & $(2)(3)(4)(6)(7)$ \\
\hline $\mathbf{4}$ & F & 40 & 21 & $(1)(2)(3)(4)(5)(6)(7)$ \\
\hline $\mathbf{5}$ & F & 35 & 26 & $(1)(3)(4)(5)(6)(7)$ \\
\hline $\mathbf{6}$ & M & 20 & onset in & childhood \\
\hline $\mathbf{7}$ & M & 44 & 31 & $(4)(4)(5)(6)(7)$ \\
\hline $\mathbf{8}$ & F & 35 & 14 & $(3)(4)(5)(6)(7)$ \\
\hline $\mathbf{9}$ & F & 51 & 4 & $(2)(3)(4)(5)(6)(7)$ \\
\hline $\mathbf{1 0}$ & F & 56 & 3 & $(2)(3)(4)(5)(6)(7)$ \\
\hline $\mathbf{1 1}$ & F & 66 & 7 & $(1)(2)(4)$ \\
\hline
\end{tabular}

F: female, M: male; body areas affected by dystonia in reference of BFMDRS : (1) eyes, (2) mouth, (3) speech and swallowing, (4) neck, (5) trunk, (6) superior limbs, (7) inferior limbs. 
Table 3. Speech tasks and associated: function assessed, instructions, measured parameters and perceptual deficits

\begin{tabular}{|c|c|c|c|}
\hline Speech tasks and function assessed & Instructions & $\begin{array}{c}\text { Measured parameters } \\
\text { (Kent, et al., 1999; Rusz, et al., 2011) }\end{array}$ & $\begin{array}{l}\text { Related perceptual deficits } \\
\text { (as defined by Darley et al., 1969; Auzou \& Rolland- } \\
\text { Monnoury, 2006; see,Supplementary data 1) }\end{array}$ \\
\hline \multirow[b]{2}{*}{$\begin{array}{l}\text { (a) Maximum sustainance of vowel /a/ } \\
\text { Aero-phonatory control }\end{array}$} & \multirow{2}{*}{$\begin{array}{l}\text { "Please take a deep } \\
\text { breath and sustain the } \\
\text { vowel /a/, as comfortably } \\
\text { and as long as you can" } \\
\text { Task performed twice }\end{array}$} & Maximum Phonation Time (MPT), in seconds & $\begin{array}{l}\text { Item } 6 . \text { Breathy voice } \\
\text { Item 33. Respiratory control }\end{array}$ \\
\hline & & $\begin{array}{l}\text { Number of voice breaks: "number of distances between } \\
\text { consecutive pulses that are longer than } 1.25 \text { divided by } \\
\text { the pitch floor" } \\
\text { (http://www.fon.hum.uva.nl/praat/manual/Voice_1__Vo } \\
\text { ice_breaks.html). }\end{array}$ & Item 12. Voice stoppage \\
\hline \multicolumn{4}{|c|}{ Cursors of the time window are manually placed at the beginning and the end of the audio signal. } \\
\hline \multirow{7}{*}{$\begin{array}{l}\text { (b) 3-second sustainance of vowel /a/ } \\
\text { Voice (phonation) quality }\end{array}$} & \multirow{7}{*}{$\begin{array}{l}\text { "Please sustain } \\
\text { comfortably the vowel /a/ } \\
\text { for about } 3 \text { seconds" } \\
\text { Task performed } 3 \text { times }\end{array}$} & Mean fundamental frequency (F0), in $\mathrm{Hz}$ & Item 2. Pitch level (+/-) \\
\hline & & Standard deviation of F0 (F0-SD), in Hz & Item 1. Voice quality \\
\hline & & Jitter (cycle-to-cycle F0 variation), in \% & Item 1. Voice quality \\
\hline & & Mean sound pressure level (SPL), in dB & Item 3. Loudness (+/-) \\
\hline & & Standard deviation of SPL (SPL-SD), in dB & Item 1 . Voice quality \\
\hline & & Shimmer (cycle to cycle SPL variation), in \% & Item 1 . Voice quality \\
\hline & & Harmonic/Noise ratio (HNR), in $\mathrm{dB}$ & Item 4. Harsh voice \\
\hline \multicolumn{4}{|c|}{ 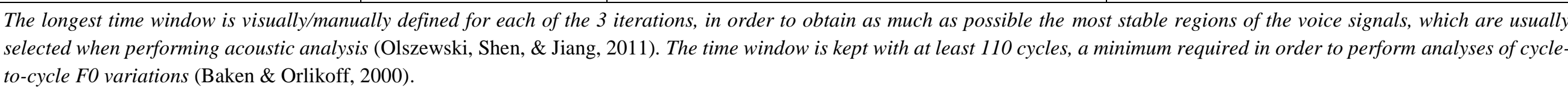 } \\
\hline \multirow{4}{*}{$\begin{array}{l}\text { (c) Oral Sequential Motion Rate (SMR) } \\
\text { Supralaryngeal articulatory control }\end{array}$} & \multirow{4}{*}{$\begin{array}{l}\text { "Please repeat the } \\
\text { pseudoword /pataka/ for } \\
30 \text { seconds, at fast rate, } \\
\text { continuously until I stop } \\
\text { you; the task will last } 30 \\
\text { seconds" } \\
\text { Task performed once }\end{array}$} & Articulatory rate, in syllables/second & Item 24. Rate $(+/-)$ \\
\hline & & $\begin{array}{l}\text { Speech proportion (= the ratio between the cumulated } \\
\text { speech durations and the total session time) }\end{array}$ & \multirow{3}{*}{ Item 33. Respiratory control } \\
\hline & & $\begin{array}{l}\text { Pauses proportion (= the ratio between the cumulated } \\
\text { pauses durations and the total session time) }\end{array}$ & \\
\hline & & Index (= speech proportion/number of breath groups) & \\
\hline \multicolumn{4}{|c|}{ 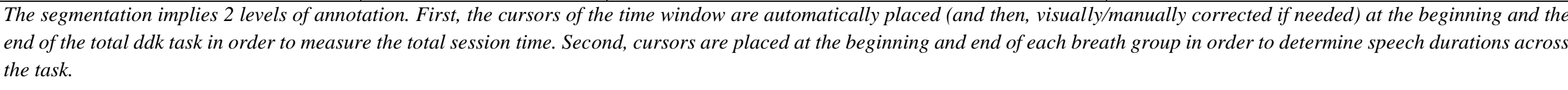 } \\
\hline & & Standard deviation of $\mathrm{F} 0$, in $\mathrm{Hz}$ & Item 20. Monopitch \\
\hline
\end{tabular}




\begin{tabular}{|c|c|c|c|}
\hline \multirow{9}{*}{$\begin{array}{l}\text { (d) Text reading } \\
\text { Prosodic features } \\
\text { Speech temporal organization }\end{array}$} & \multirow{9}{*}{$\begin{array}{l}\text { "Please read this short text } \\
\text { at normal rate, at } \\
\text { conversational rate" } \\
\text { Task performed once }\end{array}$} & & Item 21. Excess pitch variation \\
\hline & & Standard deviation of SPL, in $\mathrm{dB}$ & $\begin{array}{l}\text { Item 22. Monoloudness } \\
\text { Item 23. Excess loudness variation }\end{array}$ \\
\hline & & Total text duration, in seconds & \multirow{3}{*}{ Item 33. Respiratory control } \\
\hline & & $\begin{array}{l}\text { Total speech duration (= cumulated syllables durations, } \\
\text { without pauses) }\end{array}$ & \\
\hline & & $\begin{array}{l}\text { Total duration of pauses (= cumulated pause durations, } \\
\text { without speech) }\end{array}$ & \\
\hline & & Number of pauses & \multirow{2}{*}{$\begin{array}{l}\text { Item 27. Dysfluency } \\
\text { Item 28. Inappropriate silences } \\
\text { Item 29. Palilalia }\end{array}$} \\
\hline & & Number of syllables & \\
\hline & & $\begin{array}{l}\text { Speech rate (= number of syllables/total text duration, in } \\
\text { syllables/seconds) }\end{array}$ & Item 24. Rate (+/-) \\
\hline & & $\begin{array}{l}\text { Articulatory rate (number of syllables/total speech } \\
\text { duration, in syllables/seconds) }\end{array}$ & Item 24. Rate (+/-) \\
\hline \multicolumn{4}{|c|}{ 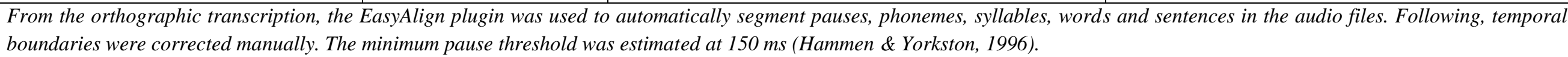 } \\
\hline \multirow[b]{2}{*}{$\begin{array}{l}\text { (e) Intelligibility assessment } \\
\text { Speech intelligibility assessment }\end{array}$} & \multirow[b]{2}{*}{$\begin{array}{l}\text { "Please read the following } \\
\text { words and sentences I will } \\
\text { be showing you, at } \\
\text { conversational rate" } \\
\text { Task performed once }\end{array}$} & Correct responses, in $\%$ & Item 34. Intelligibility \\
\hline & & $\begin{array}{l}\text { For each stimulus, rating of speech quality using a 5- } \\
\text { point scoring scale (0: speech is normal; } 1 \text { : speech is } \\
\text { abnormal but understandable; } 2 \text { : speech is moderately } \\
\text { altered; } 3 \text { : speech is severely impaired; } 4 \text { : speech is } \\
\text { unintelligible) }\end{array}$ & Item 35. Naturalness/bizarreness \\
\hline \multicolumn{4}{|c|}{ 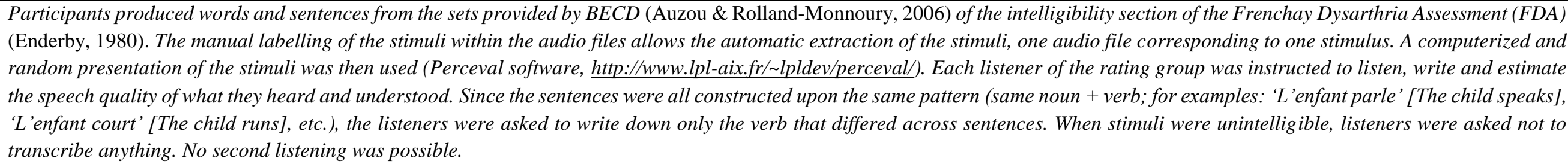 } \\
\hline
\end{tabular}


Table 4. Clinical/perceptual assessments and self-questionnaires of daily-living activities in patients with ID.

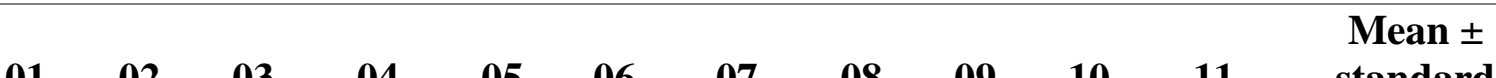

$\begin{array}{ll}01 & \text { standard } \\ \text { deviation }\end{array}$

a. clinical assessment of dystonia

\begin{tabular}{|c|c|c|c|c|c|c|c|c|c|c|c|c|}
\hline BFM-DRS Total (0-120) & 73.5 & 30.5 & 30 & 23 & 64.5 & 82 & 22 & 14 & 27 & 45 & 9.5 & $38.3 \pm 24.6$ \\
\hline BFM-DRS Speech/Swallowing (0-16) & 9 & 0 & 4 & 2 & 6 & 12 & 0 & 2 & 1 & 1 & 0 & $3.4 \pm 4$ \\
\hline BFM-DRS Mouth (0-16) & 4.5 & 0 & 2 & 0.5 & 0 & 8 & 0 & 0 & 6 & 6 & 0.5 & $2.5 \pm 3$ \\
\hline BFM-DRS Trunk (0-24) & 12 & 1 & 0 & 4 & 12 & 8 & 0 & 4 & 12 & 12 & 0 & $5.9 \pm 5.4$ \\
\hline BFM-DRS Neck (0-24) & 8 & 6 & 6 & 2 & 4 & 6 & 6 & 4 & 6 & 3 & 8 & $5.4 \pm 1.9$ \\
\hline \multicolumn{13}{|l|}{ b. self-assessment of quality of life } \\
\hline SF-36 Total $(0-100)$ & 40.7 & 85.3 & 72.6 & 72.8 & 36.3 & 67.6 & 85.1 & 49.7 & 37.2 & 41.7 & 44.3 & $57.6 \pm 19.3$ \\
\hline CDQ-24 Total $(0-100)$ & 46 & 60 & 68 & 60 & 53 & 68 & 64 & 46 & 91 & 72 & 88 & $65.1 \pm 14.8$ \\
\hline \multicolumn{13}{|l|}{ c. clinical assessment of dysarthria } \\
\hline BECD total $(0-140)$ & 69 & 35 & 76 & 25 & 58 & 87 & 7 & 10 & 17 & 29 & 20 & $39.4 \pm 28.2$ \\
\hline BECD Perceptive score $(0-20)$ & 18 & 6 & 19 & 7 & 11 & 20 & 2 & 3 & 4 & 7 & 5 & $9.3 \pm 6.7$ \\
\hline BECD Voice quality $(0-4)$ & 4 & 1 & 4 & 2 & 1 & 4 & 1 & 1 & 1 & 1 & 1 & $1.9 \pm 1.4$ \\
\hline BECD Articulatory accuracy (0-4) & 4 & 1 & 4 & 1 & 2 & 4 & 0 & 0 & 1 & 2 & 1 & $1.8 \pm 1.5$ \\
\hline BECD Prosody (0-4) & 2 & 3 & 3 & 2 & 3 & 4 & 0 & 1 & 1 & 2 & 1 & $2.0 \pm 1.2$ \\
\hline BECD Intelligibility (0-4) & 4 & 0 & 4 & 0 & 1 & 4 & 0 & 0 & 0 & 0 & 0 & $1.2 \pm 1.8$ \\
\hline BECD Naturalness/bizareness (0-4) & 4 & 1 & 4 & 2 & 4 & 4 & 1 & 1 & 1 & 2 & 2 & $2.4 \pm 1.4$ \\
\hline \multicolumn{13}{|l|}{ d. clinical assessment of voice } \\
\hline $\mathrm{G}(0-3)$ & 3 & 1 & 3 & 2 & 3 & 3 & 0 & 1 & 1 & 1 & 1 & $1.7 \pm 1.1$ \\
\hline $\mathrm{R}(0-3)$ & 3 & 0 & 3 & 2 & 2 & 3 & 0 & 0 & 0 & 0 & 0 & $1.2 \pm 1.4$ \\
\hline $\mathrm{B}(0-3)$ & 3 & 1 & 3 & 3 & 1 & 3 & 0 & 1 & 1 & 1 & 1 & $1.6 \pm 1.1$ \\
\hline $\mathrm{A}(0-3)$ & 3 & 1 & 3 & 2 & 3 & 3 & 0 & 1 & 1 & 1 & 0 & $1.6 \pm 1.2$ \\
\hline$S(0-3)$ & 3 & 0 & 3 & 1 & 3 & 3 & 0 & 1 & 1 & 0 & 1 & $1.5 \pm 1.3$ \\
\hline \multicolumn{13}{|l|}{ e. speech intelligibility } \\
\hline Word intelligibility (\% correct words) & $53 \%$ & $68 \%$ & $49 \%$ & $57 \%$ & $82 \%$ & $2 \%$ & $91 \%$ & $71 \%$ & $79 \%$ & $80 \%$ & $89 \%$ & $66 \% \pm 25 \%$ \\
\hline Sentence intelligibility (\% correct sentences) & $62 \%$ & $99 \%$ & $51 \%$ & $100 \%$ & $96 \%$ & $6 \%$ & $100 \%$ & $99 \%$ & $91 \%$ & $97 \%$ & $100 \%$ & $82 \% \pm 30 \%$ \\
\hline Qualitative rating of word intelligibility (0-4) & 3.2 & 0.5 & 1.9 & 1.2 & 1.0 & 3.8 & 0.2 & 0.4 & 0.8 & 0.4 & 0.3 & $1.2 \pm 1.2$ \\
\hline Qualitative rating of sentence intelligibility (0-4) & 2.9 & 0.3 & 1.9 & 0.7 & 1.2 & 3.8 & 0.3 & 0.1 & 0.6 & 0.7 & 0.3 & $1.2 \pm 1.3$ \\
\hline
\end{tabular}


Burke Fahn Marsden-Dystonia Rating Scale (BFM-DRS ; Burke et al., 1985); GRBAS scale (Hirano, 1981) : Grade, Roughness, Breathness, Asthenia, Strain; BECD : French Dysarthria Clinical Evaluation Battery (Batterie d'Evaluation Clinique de la Dysarthrie - Auzou \& Rolland-Monnoury, 2006); SF-36 : 36Item Short Form Health Survey (Ware \& Sherbourne, 1992); CDQ-24: 24-item Cervical Dystonia Questionnaire (Muller, 2004). Green: mild dysarthria (0 $\leq$ BECD Perceptive score $\geq 5$ ); yellow: moderate dysarthria $(6 \leq$ BECD Perceptive score $\geq 10)$; orange: marked dysarthria $(11 \leq$ BECD Perceptive score $\geq 15)$; Red: severe dysarthria $(16 \leq$ BECD Perceptive score $\geq 20)$. 
Table 5. Patients with IGD and control participants between-group comparisons of speech parameters for the following tasks: (a) maximum sustainance of vowel /a/, (b) 3-second sustainance vowel /a/, (c) oral Sequential Motion Rate (SMR) and (d) text reading.

\begin{tabular}{|c|c|c|c|}
\hline & HC & ID & p-value \\
\hline \multicolumn{4}{|c|}{ a. Maximum sustainance of vowel /a/ } \\
\hline Maximum Phonation Time (sec) & $15.2 \pm 6.8$ & $9.2 \pm 5.1$ & 0.005 \\
\hline Mean of voice breaks & $0.05 \pm 0.2$ & $3.1 \pm 5.3$ & 0.001 \\
\hline \multicolumn{4}{|l|}{ b. 3-second sustainance vowel /a/ } \\
\hline F0 normalized (Z-score) & $0.00 \pm 1.01$ & $-0.03 \pm 0.93$ & 0.898 \\
\hline $\mathrm{F} 0$ - men $($ mean, $\mathrm{Hz})$ & $102.5 \pm 25.3$ & $112.3 \pm 19.3$ & 0.046 \\
\hline $\mathrm{F} 0$ - women (mean, $\mathrm{Hz})$ & $194.8 \pm 20.4$ & $188.5 \pm 20.5$ & 0.266 \\
\hline Standard deviation of F0 (Hz) & $1.6 \pm 0.7$ & $7.7 \pm 13.3$ & 0.001 \\
\hline Jitter (\% local) & $1 \% \pm 0 \%$ & $1 \% \pm 1 \%$ & 0.327 \\
\hline SPL (mean, dB) & $75.4 \pm 3.1$ & $65.0 \pm 11.5$ & 0.001 \\
\hline Standard deviation of SPL (dB) & $0.8 \pm 0.5$ & $1.9 \pm 1.3$ & 0.001 \\
\hline Shimmer (\% local) & $2 \% \pm 1 \%$ & $6 \% \pm 6 \%$ & 0.001 \\
\hline $\mathrm{HNR}(\mathrm{dB})$ & $26.7 \pm 2.4$ & $19.4 \pm 6.0$ & 0.001 \\
\hline \multicolumn{4}{|c|}{ c. Oral Sequential Motion Rate task } \\
\hline Articulatory rate $(\mathrm{sec})$ & $5.3 \pm 0.9$ & $4.2 \pm 2.1$ & 0.365 \\
\hline Speech proportion (sec) & $0.9 \pm 0.09$ & $0.9 \pm 0.9$ & 0.397 \\
\hline Pause proportion (sec) & $0.1 \pm 0.09$ & $0.2 \pm 0.1$ & 0.421 \\
\hline Index & $0.2 \pm 0.09$ & $0.2 \pm 0.2$ & 0.638 \\
\hline \multicolumn{4}{|l|}{ d. Text reading } \\
\hline Standard deviation of F0 (Hz) & $27.6 \pm 13.7$ & $32.3 \pm 17.6$ & 0.197 \\
\hline Standard deviation of SPL (dB) & $10.6 \pm 3.6$ & $8.3 \pm 2.8$ & 0.007 \\
\hline Total text duration $(\mathrm{sec})$ & $60.6 \pm 7.5$ & $67.2 \pm 14.6$ & 0.973 \\
\hline Total speech duration (sec) & $48.04 \pm 3.7$ & $51.0 \pm 7.1$ & 0.918 \\
\hline Total duration of pauses (sec) & $12.5 \pm 4.4$ & $16.2 \pm 8.5$ & 0.756 \\
\hline Number of pauses & $25.5 \pm 7.9$ & $33.8 \pm 10.7$ & 0.340 \\
\hline Number of syllables & $241.7 \pm 4.1$ & $241.4 \pm 9.3$ & 0.416 \\
\hline Speech rate (sec) & $4.05 \pm 0.5$ & $3.7 \pm 0.8$ & 0.426 \\
\hline Articulatory rate (sec) & $5.05 \pm 0.4$ & $4.9 \pm 0.7$ & 0.597 \\
\hline
\end{tabular}

Mean \pm standard deviation (SD); Hz: Hertz; dB: Decibel; Patients 09 and 11 did not read the text entirely (instruction misunderstandings), and consequently, only the following parameters were calculated and included in the analysis for these patients: standard deviations of fundamental frequency (F0) and sound pressure level (SPL), and speech and articulatory rates. The calculation of the text reading variables was not possible at all for patient 6 , who was unintelligible, and therefore excluded from the analyses. 